\title{
A PERFORMANCE MEASUREMENT MODEL FOR MANUFACTURING COMPANIES TO DETERMINE THEIR STRENGTHS AND WEAKNESSES IN CRITICAL ACTIVITIES
}

\begin{abstract}
This paper aims to develop a comprehensive performance measurement model, which not only determines a manufacturing company's overall performance among in its industry but also obtains its strengths and weaknesses in various critical activities (areas). The proposed model has a hierarchical structure, which lets one to combine a company's performance level in critical areas with important industry-specific objectives and obtain a single overall performance score. On the other hand, the comparison of a company's performance in critical areas and objectives with respect to its competitors indicates the areas that should be improved in a quality improvement program.

Keywords: Performance measurement; Manufacturing companies; Multi-criteria decision-making (MCDM); Analytic Hierarchy Process (AHP); Technique for Order Preference by Similarity to Ideal Solution (TOPSIS)
\end{abstract}

\section{Introduction}

The proposed model uses critical areas instead of financial ratios or non-financial measures. The critical areas are specific enough such that a company can easily locate itself in one of each area's four levels provided in scorecards. The scorecards also imply what a company must do in each area to improve its performance. The proposed model's key difference from other performance measurement models is the development of performance scorecards for critical areas. The personnel, activities, practices, capabilities, investments and programs of Turkish domestic manufacturing industries are paid attention to in the determination of the areas and performance levels in these areas.

\section{Literature Review}

In the literature, the critical areas at which the companies' performance are measured are included in the determination of the performance scores of the companies (Aydogan, 2011; De Fellice and Patrillo, 2015; Ezzabadi et al., 2015; and Wang et al., 2010). These studies generally focus on developing analytical prioritization and ranking methods. On the other hand, various performance measurement models focus on the reasons of success and provide the descriptions of good and bad practices. There is a need to combine these two separate groups of studies by developing performance scorecards in which companies can analyze their performance in critical areas and combine the separate scores in critical areas into aggregate scores to compare their performance with respect to their competitors.

\section{Hypotheses/Objectives}

Performance measurement model uses critical areas to measure the performance of a manufacturing company with respect to its competitors and determine its weaknesses and strengths. The scorecard approach selected in this study structures the decision process and prevents assignment of a random score for performance evaluation of a company in each area. In development of performance scorecard the descriptions of good and bad practices are converted to four-level scale. Using performance scorecards companies can review their performances. In this study, the AHP approach is used to weight the areas 
ISAHP Article: A Performance Measurement Model for Manufacturing Companies to Determine their Strengths and Weaknesses in Critical Activities To Be Submitted to the International Symposium on the Analytic Hierarchy Process 2016, London, U.K.

with respect to objectives. The weights of the critical areas and objectives and performance scores are combined to obtain aggregated scores by using TOPSIS approach.

\section{Research Design/Methodology}

The objectives and performance scorecards are developed using the WCM and TQM literature and information obtained during the authors' visits to manufacturing companies located in Ankara. The discussions with the manufacturing companies' plant managers or executives/managers in charge of their product design, manufacturing and investment functions led to improvements in the performance scorecards and objectives. Once the model is developed, manufacturing companies determined their performance scores at critical areas and assigned relative importance values of the areas and the four objectives.

\section{Data/Model Analysis}
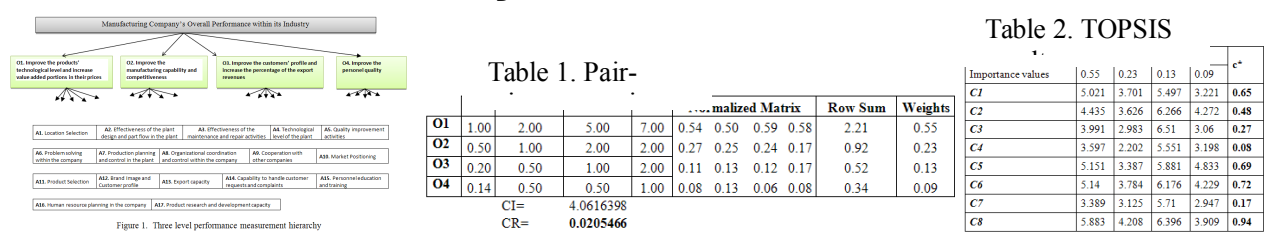

\section{Limitations}

It is difficult to develop a single performance model that is representative of all different industry types. In an application for a specific industry, the performance scorecards and objectives may require modification before its usage. The user needs to clearly define the industry type and determine its characteristics first.

\section{Conclusions}

This paper developed a performance measurement model using the AHP and TOPSIS approach. With the model, the companies can compare their ranking scores with the industry average, maximum and minimum scores and determine the weak areas. It must also be noted that weights of the areas and objectives are obtained as an outcome of the proposed model. A higher-weighted component is considered more important in the performance of a company. A low performance score against a high-weighted measure may require special attention of the management.

\section{Key References}

Aydogan, E.K. (2011). Performance measurement model for Turkish aviation firms using the rough-AHP and TOPSIS methods under fuzzy environment . Expert Systems with Applications, 38, 3992-3998.

Sun, C-C. (2010). A performance evaluation model by integrating fuzzy AHP and fuzzy TOPSIS methods. Expert Systems with Applications, 37, 7745-7754.

Ezzabadi, J.H., Saryazdi, M.D., Mostafaeipour, A. (2015) Implementing Fuzzy Logic and AHP into the EFQM model for performance improvement: A case study. Applied Soft Computing, 36, 165-176.

Wang, C-H., Lu, I.Y., Chen, C-B. (2010). Integrating hierarchical balanced scorecard with non-additive fuzzy integral for evaluating high technology firm performance. Int. J. Production Economics, 128, 413-426. 
ISAHP Article: A Performance Measurement Model for Manufacturing Companies to Determine their Strengths and Weaknesses in Critical Activities To Be Submitted to the International Symposium on the Analytic Hierarchy Process 2016, London, U.K.

De Felice, F., Petrillo A. (2015). Optimization of Manufacturing System through World Class Manufacturing. IFAC Papers On-line, 48(3), 741-746. 